\title{
The Effect of the Thickness-to-Die Diameter Ratio on the Sheet Metal Blanking Process
}

\author{
Kaan Emre Engin ${ }^{1, *}$ - Omer Eyercioglu ${ }^{2}$ \\ ${ }_{1}^{1}$ Adiyaman University, Faculty of Technology, Automotive Engineering Department, Turkey \\ ${ }^{2}$ Gaziantep University, Engineering Faculty, Mechanical Engineering Department, Turkey
}

The blanking process has a wide range of usage in the sheet metal production industry. The effectiveness of the process rests on the balance between the surface quality of the blanks and energy conservation during the process. The effects of different process parameters on surface quality and energy efficiency have been studied by researchers, but there is a gap concerning the effect of the thickness-to-die diameter ratio on surface quality and energy efficiency. In this study, four different thickness-to-die diameter ratios $\left(t / D_{m}=1 / 5, t / D_{m}=1 / 10, t / D_{m}=1 / 30\right.$ and $t / D_{m}=1 / 50$ ) with five different clearances (1\%, $3 \%, 5 \%, 10 \%$, and $20 \%$ of thickness) were used to blank 2-mm-thick round workpieces made of AISI 304 stainless steel. Both experimental and FEM studies were accomplished. A special die set was manufactured and a hydraulic press was used for experimental studies. For FEM studies, Deform-2D was used. Investigations were made on the effects of different thickness-todie diameter ratios on the blanking force, cutting energy crack propagation angles, and zone distribution related to surface quality. Results gathered from FEM simulations and experimental studies were coherent with each other.

Keywords: blanking process, blanking parameters, shear zone, clearance

Highlights

- A common stainless steel (AISI 304) with $2 \mathrm{~mm}$ thickness were blanked by four different thickness-to-die diameter ratios $\left(t / D_{m}=1 / 5, t / D_{m}=1 / 10, t / D_{m}=1 / 30\right.$ and $\left.t / D_{m}=1 / 50\right)$ and under five different clearances $(1 \%, 3 \%, 5 \%, 10 \%$, and $20 \%$ of thickness) for each ratio.

- Both experimental and FEM investigations were accomplished. A special die set with changeable die and punches were manufactured and a hydraulic press with different loading capabilities was used for experimental investigations. Deform-2D was used for FEM investigations.

- $\quad$ The ideal cutting condition is the point at which the cutting energy is lowest and surface quality is at best.

- It was determined that the ideal cutting condition can be achieved at $3 \%$ clearance for $t / D_{m}=1 / 5$ and $t / D_{m}=1 / 10$ and at $5 \%$ clearance for $t / D_{m}=1 / 30$ and $t / D_{m}=1 / 5$.

- $\quad$ The change in $t / D_{m}$ ratio changes punch load, stroke depth and cutting energy. The ratio difference also has a small effect on the clearance value.

\section{INTRODUCTION}

The blanking process has an important usage in sheet metal forming applications. The process of blanking can be described as the shearing of the workpiece (sheet metal) into the desired shape (blank), which is pressed on to the lower die by a blankholder and then perforated by the upper die (punch). The sheet metal part undergoes large elastoplastic deformations that lead to the development of damage and eventually complete fracture of the material [1].

Although the general aspects of blanking seem simple, many parameters govern the process, and all of them have their own effects on the quality of the blanks. The general process parameters include the clearance, material type and thickness, cutting velocity, tool geometry, tool wear, and kinematic of the press [2].

For many years, researchers have been attempting to determine the effects of some of these parameters and related outcomes in the blanking process using experimental and numerical (finite element) methods. Some recent examples are as follows. Lubis and Mahardinka [3] studied the effect of clearance and cutting velocity on the sheared surface of copper sheets experimentally and observed the positive effects of high cutting velocities. Swillo and Czyzewski [4] examined the effect of different clearances on the material fracture by experimental and numerical methods. Wu et al. [5] used three different clearances for blanking high strength steels and proposed a new calculation method to characterize strain distribution in the sheared region. Mucha [6] attempted to observe the effect of clearance, tool coatings, and tool materials on the wear of blanking tools. Col et al. [7] investigated the tool wear of $\mathrm{AlCrN}$ coated punches during blanking with experimental methods. Wang et al. [8] also tried to observe the different wear characteristics of different die materials in high strength steel blanking. Bolka et al. [9] studied the identification of the material characteristics and damage correlation through in and out-of- plane direction for blanking 
with experimental methods. Subramonian et al. attempted to determine the interaction between the punch, stripper plate and sheet material under various speeds in blanking; furthermore, the effect of punch velocity on the blanking load was investigated in this study [10] and in another [11]. Kanca et al., showed the effect of blanking speed on the surface quality of mild [12] and stainless-steel blanks [13]. Al-Momani et al. [14] developed and compared two models based on an artificial neural network and a multiple regression analysis to predict the burr height as a representation of surface quality. $\mathrm{Hu}$ et al. [15] used a FEM method to investigate the heat generation at the shear zone due to different blanking speeds. Magesh et al. [16] examined the effect of different clearances on the shearing and wrinkling behaviour of AISI 316 stainless steel by using a FEM method. Hambli et al. proposed using a FEM method and neural network analysis to optimize the clearance between punch and die [17] and [18]. Mole et al. [19] proposed a new FEM method to optimize the blank shape. Behrens et al. [20] focused on the effect of speed and clearance to the blank load and sheared surface geometry distribution. Soares et al. [21] examined the effect of clearance on the sheared edge quality of thick sheets ( $8 \mathrm{~mm})$ by FE- simulations.

It can be understood that research studies involving blanking parameters are many and cover various aspects of the procedure by experimental and FEM methods. However, it was realized that the size of a blank should also have an effect because the desired blanked product for different industrial applications can vary greatly in size. One of the most important advantages of blanking is that different sizes can be produced efficiently by proper tooling. The researchers who tried to investigate different aspects of blanking did not consider the size parameter and its outcomes, which led to a gap in the blanking literature.

In this paper, four different thickness-to-die diameter ratios $\left(t / D_{m}=1 / 5, t / D_{m}=1 / 10, t / D_{m}=1 / 30\right.$ and $\left.t / D_{m}=1 / 50\right)$ with five different clearances $(1 \%$, $3 \%, 5 \%, 10 \%$, and $20 \%$ of thickness) were used to blank round workpieces made of AISI 304 stainless steel. Both experimental and numerical methods were used to determine the effect of ratio differences and clearances on the blanking force, cutting energy, and crack propagation angles related to surface quality.

\section{PROCESS PARAMETERS}

\subsection{Finite Element Model}

Experimental methods to observe blanking often rely on trial-and-error procedures that require excessive time and money. One of the most economical and less time-consuming approaches to observe blanking is modelling the process by using the finite element method (FEM). The user can simulate the process by defining all variables, including material properties, speed of the punch, contact conditions at all the interfaces, etc.

For this study, the Deform-2D package, which is a product of the Scientific Forming Technologies Corporation (STFC) was used to make the FEM models. This FEM code is based on an implicit Lagrangian computational routine [18]. The blanking process was considered axisymmetric, and a 2D model was used to simulate the process parameters. Thus, modelling only one half of the tooling is enough for executing the runs.

The blanking setup considered for simulations is given in Fig. 1. The setup has four components: The punch, lower die, sheet material, and a blank holder to hold the sheet stock for unwanted bending during the blanking process. The sheet material was considered to be a plastic object whereas the punch, die and blank holder were considered rigid bodies. Friction between the workpiece and tools was assumed to follow constant shear friction.

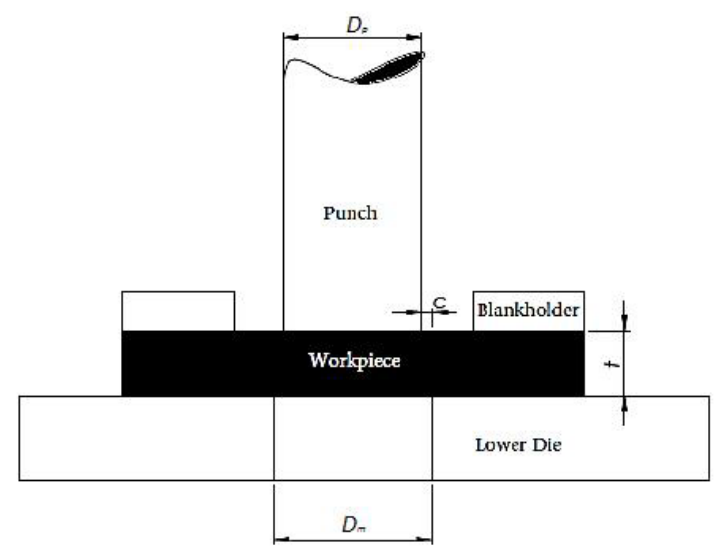

Fig. 1. The blanking setup for simulations

The frictional force in this type of definition is expressed in Eq. 1 as;

$$
f_{s}=m k,
$$


where $f_{s}$ is the frictional stress, $k$ is the shear yield stress, and $m$ is the friction factor. This states that the friction is a function of the yield stress of the deforming body.

In the blanking process, large plastic strain generation happens in the narrow shear zone. It was assumed that the material was isotropic and that yielding occurred according to the Von Mises yield criterion. The flow stress is expressed in Eq. (2) as:

$$
\bar{\sigma}=K \bar{\varepsilon}^{n},
$$

where $\bar{\sigma}$ is the effective stress, $\bar{\varepsilon}$ is the effective strain, $K$ is the material constant, and $n$ is the strainhardening exponent [22].

Normalized Cockroft and Latham was chosen as the fracture criterion. This criterion predicts the fracture strain more precisely than the other criterions in metal forming processes [22]. The criterion states that the fracture occurs when the effective strain reaches the critical value, expressed in Eq. (3) as:

$$
\int_{0}^{\varepsilon^{-f}}\left(\frac{\sigma^{*}}{\bar{\sigma}}\right) d \bar{\varepsilon}=C,
$$

where $\sigma^{*}$ is the maximum principal tensile stress, $\varepsilon^{-f}$ the fracture strain and $C$ is the critical value. The effective stress and effective strain are defined as $\bar{\sigma}$ and $\bar{\varepsilon}$. The critical value $C$ can be evaluated with a tensile test and does not depend on the working operation. C for AISI 304 was found experimentally by executing a tensile test.

During the blanking process, shearing of the workpiece happens in a narrow zone called the shear band. The behaviour of the shear band in shear hat test was studied by Pepelnjak et al., and they showed that the variation of medial diameter and shearing surface change is less than $1 \%[23]$. The stress ratio $\left(\sigma^{*} / \bar{\sigma}\right)$ is assumed to be constant throughout that band where the deformation is highly concentrated. Therefore, this assumption may be implemented into the Cockroft and Latham criterion and approximated by $\varepsilon^{-f}=C^{*}$ at the shear band. This approach postulates that a crack initiation occurs at the point of the sheet whose effective strain first reaches the fracture strain of the work material [17]. During the simulations, element deletion occurs when the critical values are satisfied. In the DEFORM program, the simulation stops time to time to execute element deletion; this feature has two governing parameters which are "fracture steps" and "fracture elements". Fracture steps value determines the step interval at which the simulation stops and performs element deletion. This value was chosen as ' 1 ', which is the minimum value. This means that element deformation is taken into account in each step. Fracture elements are the number of the elements that must be above the critical damage value for the simulation to stop and perform element deletion. This value was chosen as ' 4 ' as the system default.

As mentioned, the deformation and crack propagation happen in a narrow zone within the punch die clearance. If critical values are satisfied, the simulation stops and performs element deletion in this zone, according to the fracture steps and fracture elements values. However, element deletion from the components in simulation causes volume loss and may lead to incorrect calculations. To prevent and limit volume degradation, a very fine mesh must be used, and mesh elements should be concentrated where a probable fracture occurrence is expected. First, 10,000 isoparametric quadratic elements with 0.03 $\mathrm{mm}$ element size were used as the element meshes of the sheet; these are the highest element number values that can be defined in Deform. Then, by using equally spaced mesh density windows created specifically for different ratios, mesh elements were equally concentrated (to the greatest degree possible) around the deformation zone. These mesh windows move with the punch and constantly try to discretize the sheet surface within specific mesh densities when remeshing. The geometrical model of the blanking process and the FEM meshes of the workpiece were given in Fig. 2.

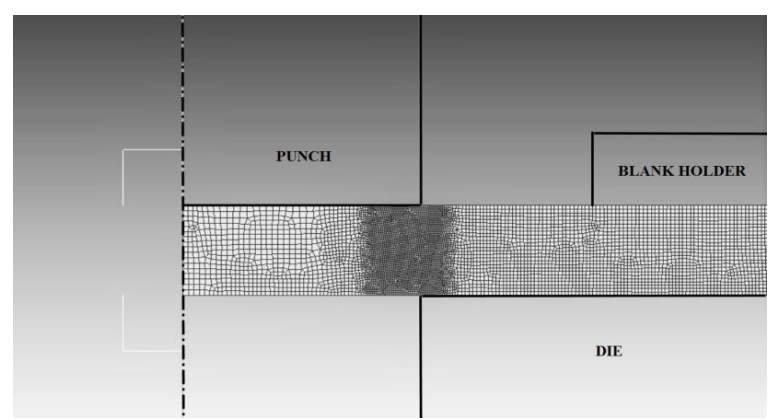

Fig. 2. The geometrical model of the blanking process and the FEM meshes of the workpiece

\subsection{Ideal Cutting Condition and Crack Propagation Angles}

The ideal cutting condition occurs when the punch load is the lowest for energy conservation, and the quality of the blanked part is so good that no extra labour is needed to correct the defects on the blanked part surfaces. This means that the shear zone (indentation) depth is at least one third of the sheet thickness, and no 
burr is forming. The ideal cutting condition is achieved when the angle of real crack propagation direction $\beta$ coincides with the angle of ideal crack propagation direction $\theta$. The real crack propagation direction is the actual direction of crack propagation, which is formed on the blank surface, whereas the ideal crack propagation direction is the desired path of the crack propagation towards the cutting edges of the punch and lower die. It can be mentioned that values of $\beta$ closer to values of $\theta$ result in smoother surfaces.

If the crack propagations do not coincide, secondary crack formation occurs that creates rough surfaces. The directions of angle $\beta$ and angle $\theta$ are illustrated in Fig. 3. As it is evident from Fig. 3, the real crack propagation direction does not coincide with the ideal crack propagation direction, creating secondary cracks. The equalization of ideal crack propagation angle $\theta$ and the angle of the direction of real crack propagation $\beta$ giving the ideal cutting condition can be expressed in Eq. (4) as:

$$
\Phi=\beta-\theta \cong 0 .
$$

The ideal crack propagation angle can be expressed in Eq. (5) as:

$$
\theta=\operatorname{Arctan}\left(\frac{c}{t-u_{p}}\right),
$$

where $c$ is the clearance; $t$ is the sheet metal (workpiece) thickness and $u_{p}$ is the punch penetration corresponding to the first crack initiation within the sheet.

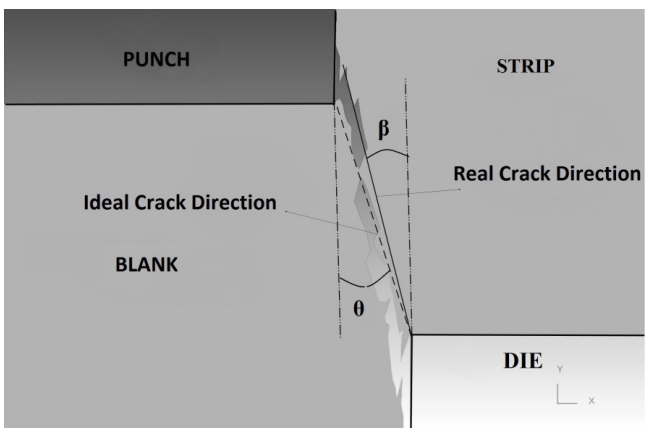

Fig. 3. Illustration of real crack propagation angle $\beta$, ideal crack propagation angle $\theta$, and secondary cracks

\section{EXPERIMENTAL}

\subsection{Material Model and Experimental Setup}

AISI 304 stainless steel was used for both simulation and experimental studies. AISI 304 is a very common type of stainless steel used in various industrial applications varying in different forms from simple hypodermic needles to marine and nuclear applications [24]. The engineering and flow curve of AISI 304 were obtained from tensile tests. A Shimadzu AG-X Plus tensile testing machine was used with a constant loading velocity of $0.01 \mathrm{~s}^{-1}$. The test was repeated 10 times at room temperature, and the engineering stressstrain curve was obtained. The flow curve of AISI 304 was calculated by using the well-known true stressstrain equations expressed in Eqs. (6) and (7) as:

$$
\begin{aligned}
& \sigma_{t}=\sigma(1+\varepsilon), \\
& \varepsilon_{t}=\ln (1+\varepsilon),
\end{aligned}
$$

where $\sigma_{t}$ and $\sigma$ are true and engineering stresses, whereas $\varepsilon_{t}$ and $\varepsilon$ are true and engineering strains, respectively.

The obtained flow curve was identified in the Deform program's database so that simulation results could meet the experimental results. The true (flow curve) and engineering stress-strain curves of AISI 304 were given in Fig. 4.

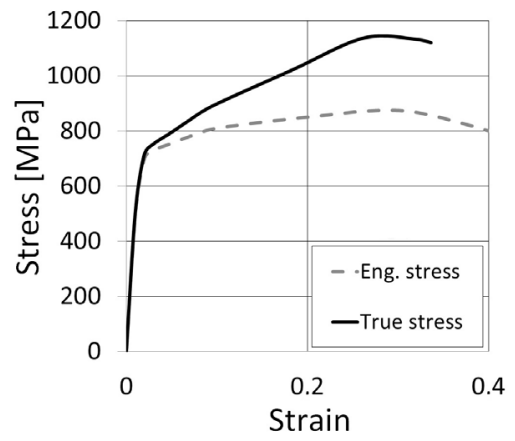

Fig. 4. Engineering and true stress-strain curves of AISI 304

The isometric and exploded view of the designed die and its components were given in Fig. 5. The die consists of six components; upper die block (1), punch (2), punch holder (3), fixed stripper (4), lower die (5) and lower die block (6).

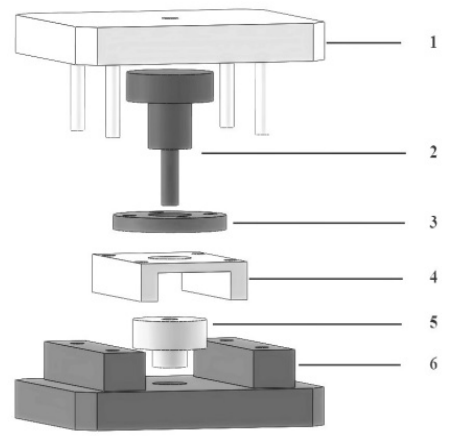

Fig. 5. The exploded view of the designed die for experiments 
The upper die block, punch holder, fixed stripper and lower die block were made of St 37 steel whereas the guide rods on the upper die block, punch and lower die were made of heat treated AISI 4140 for long durability.

The predetermined size of the blank should play a major role in the process. The same clearance values for blanks with different diameters are unlikely although their thicknesses are the same.

So, four different thicknesses to die diameter ratios $\quad\left(t / D_{m}=1 / 5, \quad t / D_{m}=1 / 10, \quad t / D_{m}=1 / 30 \quad\right.$ and $t / D_{m}=1 / 50$ ) were used to evaluate the effects of sizes. The thickness of the workpiece was taken $2 \mathrm{~mm}$. The lower die diameters were calculated according to the ratios as $10 \mathrm{~mm}, 20 \mathrm{~mm}, 60 \mathrm{~mm}$ and $100 \mathrm{~mm}$. Five different clearance values $(1 \%, 3 \%, 5 \%, 10 \%$, and $20 \%$ of thickness) were used, and punch diameters were calculated according to the clearance formula expressed in Eq. (8) as:

$$
C=100 \frac{D_{m}-D_{p}}{2 t}[\%],
$$

where $D_{m}$ is the lower die diameter, $D_{p}$ is the punch diameter, and $t$ is the workpiece thickness.

Calculated punch diameters were given in Table 1. Manufactured punches and die for $t / D_{m}=1 / 5$ were given in Fig. 6 as an example. The diameters of punches according to clearances from left to right were $1 \%(9.96 \mathrm{~mm}), 3 \%(9.88 \mathrm{~mm}), 5 \%(9.80 \mathrm{~mm})$, $10 \%(9.60 \mathrm{~mm})$, and $20 \%(9.20 \mathrm{~mm})$. The clearance between the punch and die must be precise, so punches are manufactured within a $\pm 0.01 \mathrm{~mm}$ tolerance limit.

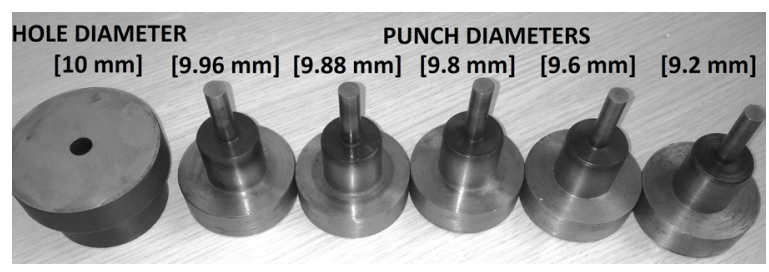

Fig. 6. One set of manufactured punches $\left(t / D_{m}=1 / 5\right)$

Table 1. Punch diameters used in simulation and experimental studies

\begin{tabular}{lcccc}
\hline \multirow{2}{*}{$C$} & \multicolumn{4}{c}{ Punch diameters [mm] } \\
\cline { 2 - 5 } & Ratio 1/5 & Ratio 1/10 & Ratio 1/30 & Ratio 1/50 \\
\hline $\mathbf{1 \%}$ & 9.96 & 19.96 & 59.96 & 99.96 \\
\hline $5 \%$ & 9.88 & 19.88 & 59.88 & 99.88 \\
\hline $10 \%$ & 9.80 & 19.80 & 59.80 & 99.80 \\
\hline $20 \%$ & 9.60 & 19.60 & 59.60 & 99.60 \\
\hline
\end{tabular}

All experiments were done by using a 300 $\mathrm{kN}$ capacity hydraulic press. Speed had been kept constant, and a $0.01 \mathrm{~m} / \mathrm{s}$ punch speed was used to execute the blanking processes.

\section{RESULTS AND DISCUSSION}

The microscopic image of a blank and the image taken from FE simulation were given in Fig. 7. As can be seen, crack propagations and related zones are similar between experimental and simulation results. The numerical values gathered from experiments and simulations (punch load, stroke, blanking energy, etc.) are also similar. The punch load difference between simulation and real experimental values for $t / D_{m}=1 / 10$ at $5 \%$ clearance were given in Fig. 8 .

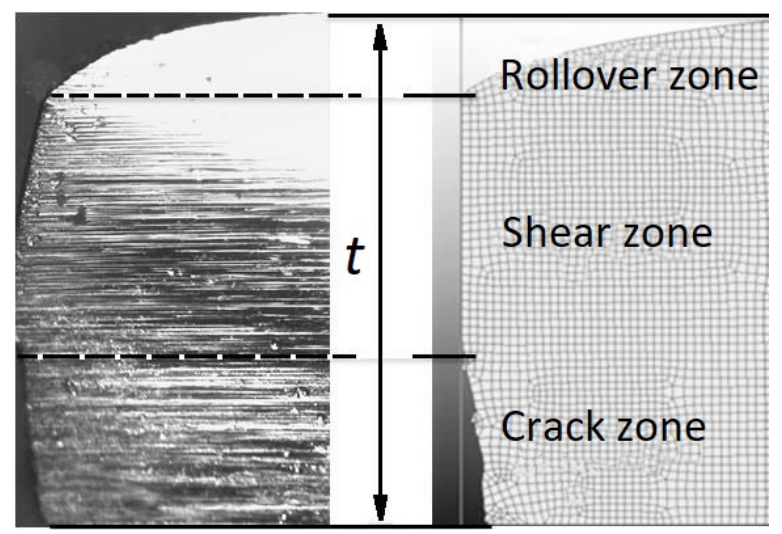

Fig. 7. The microscopic image and the simulation image of a blank $\left(t / D_{m}=1 / 10, t=2 \mathrm{~mm}\right.$, clearance: $\left.5 \%\right)$

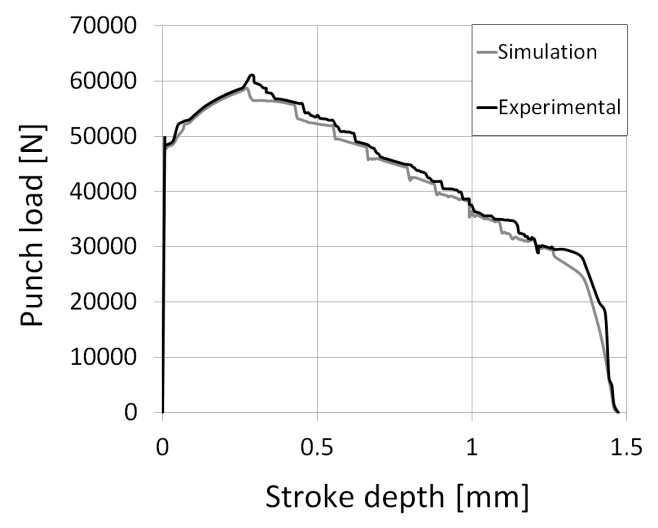

Fig. 8. Punch load difference between experimental and simulation results. (t/Dm=1/10, clearance: $5 \%)$

\subsection{Punch Load, Cutting Energy and Surface Quality}

Punch load plays an important role in blanking process. Although the gathered punch load value is 
the result of the process, and it cannot be adjusted for specific conditions, minimum required punch load for a blanking process is simply calculated in Eq. (9) as [25];

$$
F=L \times t \times \tau,
$$

where $F$ is the blanking force $[\mathrm{N}], L$ is the forming circumference $[\mathrm{mm}], t$ is the strip thickness $[\mathrm{mm}]$ and $\tau$ is the shear strength [MPa].

The punch load differences between four different $t / D_{m}$ ratios at $5 \%$ clearance were given in Fig. 9. As can be seen from Fig. 9, the punch load increases with increasing blank size as expected, and stroke depth increases with increasing $t / D_{m}$ ratios.

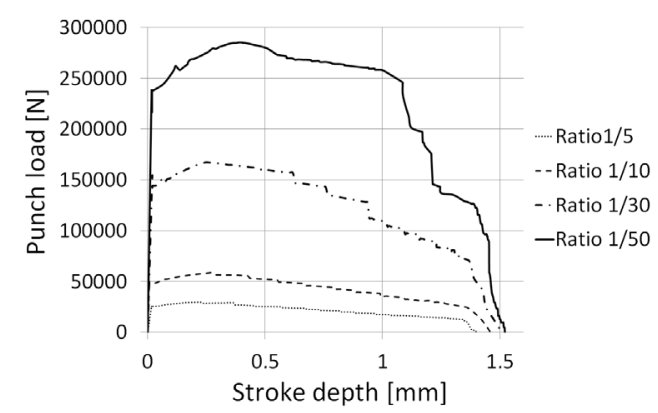

Fig. 9. Punch load difference between different $t / D_{m}$ ratios at $5 \%$ clearance

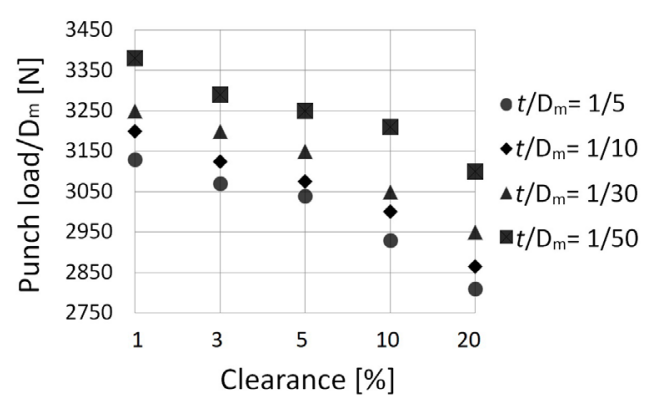

Fig. 10. Relative punch load versus clearance for different

$$
t / D_{m} \text { ratios }
$$

The differences in punch loads for four $t / D_{m}$ ratios under different clearances were given in Fig. 10. Relative punch load $\left(F / D_{m}\right)$ were used to make comparisons.

Fig. 10 shows that the punch load at every clearance increases with increasing $t / D_{m}$ ratios. Additionally, as the clearance increases for each ratio, the punch loads required to cut the blanks decrease. It may be assumed that the usage of higher clearances might be more beneficial for energy saving but taking only the punch load into consideration may lead to incorrect interpretations. Instead, taking cutting energy into consideration which is the ratio between punch load and stroke depth gives more realistic insight into the situation. Especially with changing clearance, punch load and stroke depth also change, which causes alteration in the cutting energies.

In contrast, surface quality should be taken into consideration along with cutting energy parameters. A burr-free part with good crack propagation can save on extra deburring operations, labour and extra money as well as energy efficiency. Clearance values also determine the crack propagation and zone distribution in the shear zone. It can be stated that the ideal cutting condition is where the spent energy is low and the blank's surface quality is good.

Cutting energy differences between $t / D_{m}$ ratios under different clearances were given in Fig. 11.

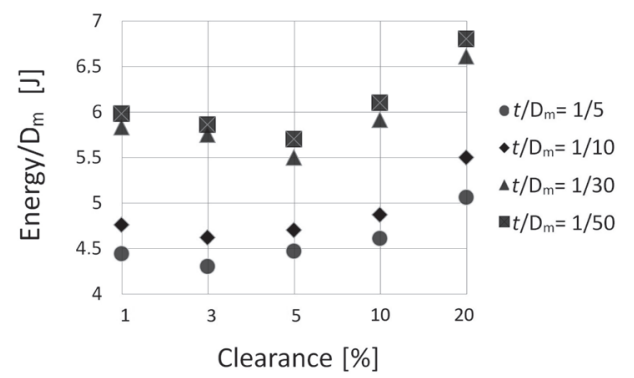

Fig. 11. Relative cutting energy difference between $t / D_{m}$ ratios under different clearances

Fig. 11 shows that the lowest cutting energies were achieved at $3 \%$ clearance for $t / D_{m}=1 / 5$ and $t / D_{m}=1 / 10$ ratios and at $5 \%$ clearance for $t / D_{m}=1 / 30$ and $t / D_{m}=1 / 50$ ratios.

Fig. 12 shows experimental and simulation images of the crack propagation on a blank $\left(t / D_{m}=1 / 5\right.$ at $5 \%$ clearance) as an example.
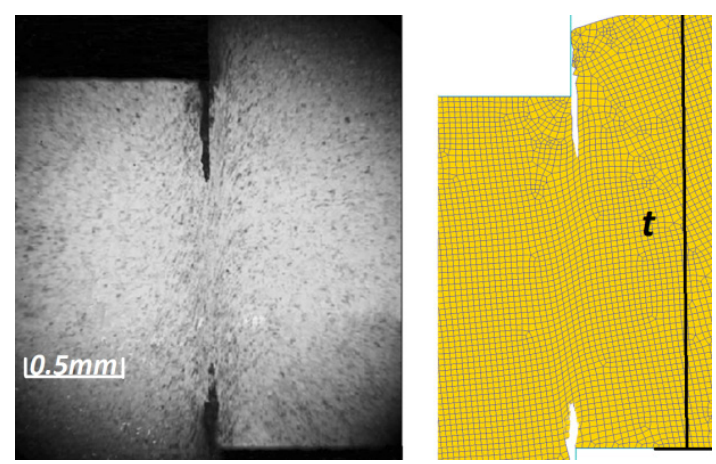

Fig. 12. Experimental and simulation images of crack propagation $\left(t / D_{m}=1 / 5, t=2 \mathrm{~mm}\right.$, clearance: $\left.5 \%\right)$

The difference between real crack propagation angle $\beta$ and ideal crack propagation angle $\theta$ was 
calculated according to $\Phi=\beta-\theta$ condition. The condition postulates that the closer $\Phi$ is to zero, the smoother the blanked surface is. The closest values to zero were found when the clearance was $3 \%$ for $t / D_{m}=1 / 5$ and $t / D_{m}=1 / 10$ and $5 \%$ clearance for $t / D_{m}=1 / 30$ and $t / D_{m}=1 / 50$ ratios. Furthermore, as the clearance increased, the difference between real crack propagation angle $\beta$ and ideal crack propagation angle $\theta$ increased which resulted in low surface quality. The differences between angles are shown in Fig. 13.

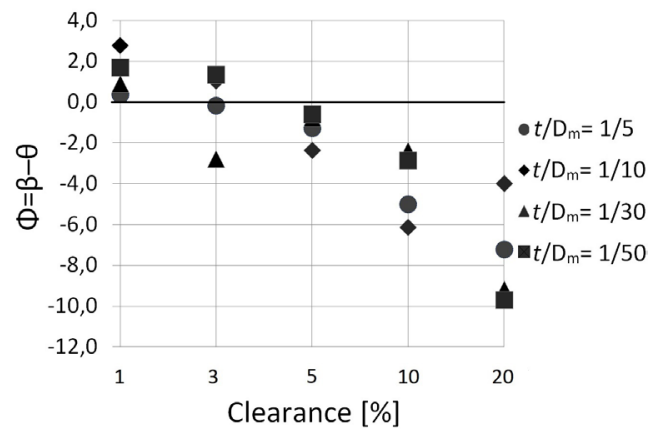

Fig. 13. The difference between real crack propagation angle ( $\beta$ ) and ideal crack propagation angle $(\theta)$

Zone distribution on the shear surface of a blank is closely related with clearance value. The amount of shear zone is also the expression of good surface quality whereas an increase in the crack zone means the opposite. The blanks for each $t / D_{m}$ ratio were given in Fig. 14.

Fig. 15 shows the microscopic image of the shear surface of the blank $\left(t / D_{m}=1 / 10\right.$, clearance: $\left.5 \%\right)$. The shear zone is the burnished part at the lower portion of the surface and crack zone is the rougher part on the upper portion.

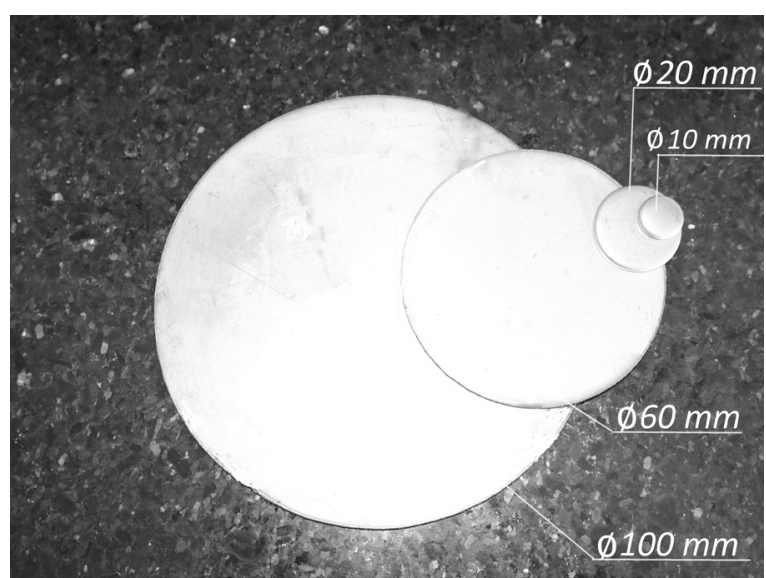

Fig. 14. Blanks for $t / D_{m}=1 / 50, t / D_{m}=1 / 30, t / D_{m}=1 / 10$ and $t / D_{m}=1 / 5$
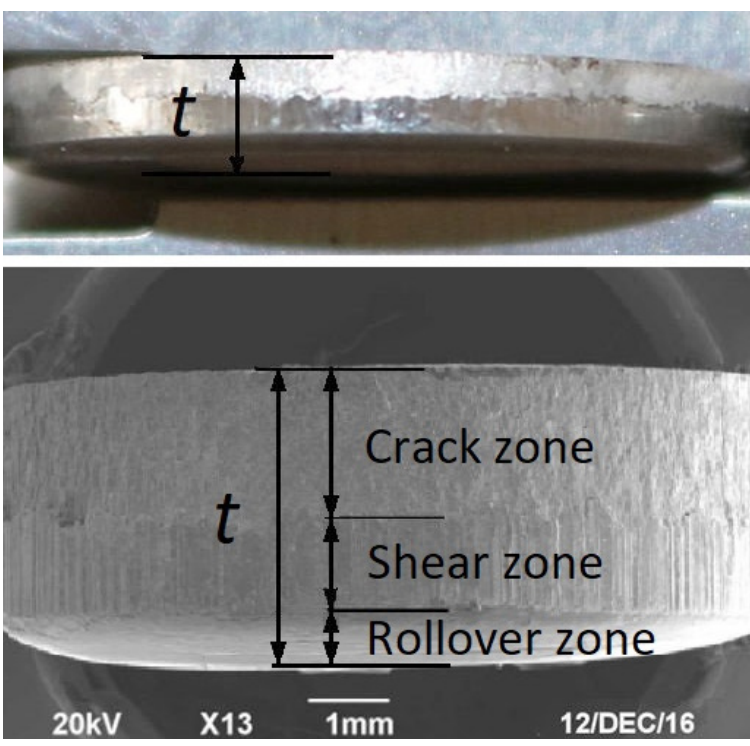

Fig. 15. Shear, crack and rollover zone distribution on a blank $\left(t / D_{m}=1 / 10, t=2 \mathrm{~mm}\right.$, clearance: $\left.5 \%\right)$

Fig. 16 shows the shear zone length percentage for all $t / D_{m}$ ratios.

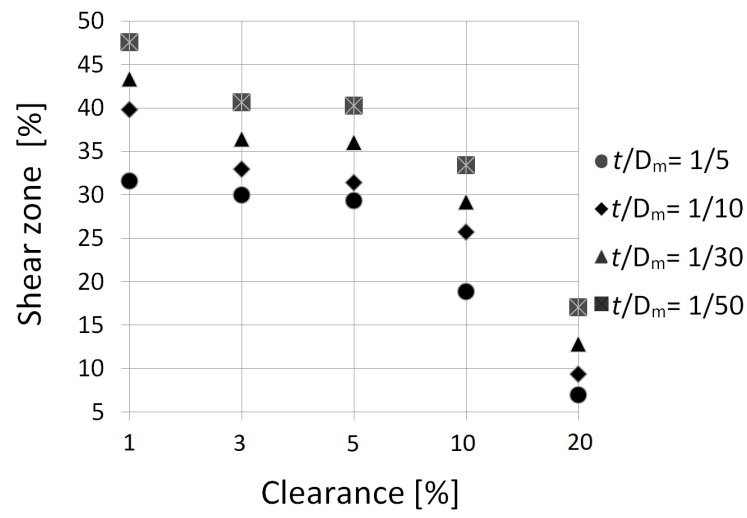

Fig. 16. Shear zone percentage for $t / D_{m}$ ratios

Fig. 16 shows that clearance affects the shear zone depth. The overly tight clearance increased the shear zone depth, but it also increased the blanking load according to Fig. 10. This situation can cause more energy to be consumed and probable early tool wear.

When the clearance became too loose, shear zone depth decreased. From Fig. 16, it can be understood that the crack zone started to dominate sheared surfaces after exceeding $10 \%$ clearance for all $t / D_{m}$ ratios. It is also evident from Fig. 13 that the real crack propagation direction diverges from the ideal direction at higher clearances, which can cause protruded surfaces. 
For higher ratios, the difference of shear zone percentage between $3 \%$ and $5 \%$ clearance is slight. Therefore, it is important to adjust the clearance value where the shear zone is long and blanking energy is low. The combined interpretation of the results leads to the point that $3 \%$ clearance is suitable for $t / D_{m}=1 / 5$ and $t / D_{m}=1 / 10$ ratios and $5 \%$ clearance is suitable for $\mathrm{t} / D_{m}=1 / 30$ and $t / D_{m}=1 / 50$ ratios when blanking AISI 304 stainless steel.

\section{CONCLUSIONS}

In this study, four different thickness-to-die diameter ratios $\left(t / D_{m}=1 / 5, \quad t / D_{m}=1 / 10, \quad t / D_{m}=1 / 30 \quad\right.$ and $\left.t / D_{m}=1 / 50\right)$ with five different clearances ( $1 \%$, $3 \%, 5 \%, 10 \%$, and $20 \%$ of the thickness) were used to blank round workpieces made of AISI 304 stainless steel. The punch load, cutting energy, crack propagation angles, and zone distributions on the blanks were observed. The following conclusions can be made;

- Blanking energy, crack propagation angles and zone distribution are related. Tool adjustment, especially the clearance adjustment should be made to achieve both aspects. There is an optimal clearance value that aligns all these parameters at the same time.

- The results have shown the ideal clearance value not only depends on material thickness, but also the thickness-to-die diameter ratio of the blank. The ideal clearance for AISI 304 at which energy saving and good surface quality can be achieved is $3 \%$ for $t / D_{m}=1 / 5$ and $t / D_{m}=1 / 10$ (blanks with small circumferences) and $5 \%$ for $t / D_{m}=1 / 30$ and $t / D_{m}=1 / 50$ (blanks with big circumferences).

- The increase in $t / D_{m}$ ratio also increases punch load, stroke depth and as a result cutting energy. When the circumference of the material with the same thickness increases, the clearance value also shows a small tendency to increase.

\section{REFERENCES}

[1] Lemiale, V., Chambert, J., Picart, P. (2009). Description of numerical techniques with the aim of predicting the sheet metal blanking process by FEM simulation. Journal of Materials Processing Technology, vol. 209, no. 5, p. 27232734, D0I:10.1016/j.jmatprotec.2008.06.019.

[2] Sidhu, K.B., Peshekhodov, I., Behrens, B.-A. (2008). Numerical modelling of high speed blanking considering thermoviscoplastic effects. 3rd International Conference on High Speed Forming, p. 97-106.

[3] Lubis, Z.D., Mahardika, M. (2016). Influence of clearance and punch velocity on the quality of pure thin copper sheets blanked parts. IOP Conference Series: Materials Science and Engineering, vol. 157, no. 1, p. 1-6, Dol:10.1088/1757899X/157/1/012012.

[4] Swillo, S., Czyzewski, P. (2013). An experimental and numerical study of material deformation of a blanking process. Computer Methods in Materials Science, vol. 13, no. 2, p. 333-338.

[5] Wu, X., Bahmanpour, H., Schmid, K. (2012). Characterization of mechanically sheared edges of dual phase steels. Journal of Materials Processing Technology, vol. 212, no. 6, p. 12091224, D0I:10.1016/j.jmatprotec.2012.01.006.

[6] Mucha, J. (2010). An experimental analysis of effects of various material tool's wear on burr during generator sheets blanking. The International Journal of Advanced Manufacturing Technology, vol. 50, no. 5, p. 495-507, D0I:10.1007/s00170-010-2554-1.

[7] Çöl, M., Kir, D., Erişir, E. (2013). Wear and blanking performance of AICrN PVD-coated punches. Materials Science, vol. 48, no. 4, p. 514-520, D0l:10.1007/s11003-013-9532-3.

[8] Wang, C., Chen, J., Yu, X., Xia, C., Ren, F. (2014). Experimental investigations on wear resistance characteristics of different die materials for advanced high-strength steel blanking in close section. Proceedings of the Institution of Mechanical Engineers, Part B: Journal of Engineering Manufacture, vol. 228, no. 11, p. 1515-1525, D0l:10.1177/0954405414521192.

[9] Bolka, Š., Slavič, J., Boltežar, M. (2015). Identification of out-ofplane material charac-teristics through sheet-metal blanking. Strojniški vestnik - Journal of Mechanical Engineering, vol. 61, no. 4, p. 217-226, D0I:10.5545/sv-jme.2014.2302.

[10] Subramonian, S., Altan, T., Campbell, C., Ciocirlan, B. (2013). Determination of forces in high speed blanking using FEM and experiments. Journal of Materials Processing Technology, vol. 213, no. 12, p. 2184-2190, D0l:10.1016/j. jmatprotec.2013.06.014.

[11] Gaudillière, C., Ranc, N., Larue, A., Maillard, A., Lorong, P. (2013). High speed blanking: An experimental method to measure induced cutting forces. Experimental Mechanics, vol. 53, no. 7, p. 1117-1126, D0l:10.1007/s11340-013-9738-1.

[12] Kanca, E., Eyercioğlu, O., Karahan, I.H., Günen, A., Göv, K. (2016). Effects of blanking speed on the shear surface of mild steel (St37). Acta Physica Polonica A, vol. 130, no. 1, p. 370 374, D0l:10.12693/APhysPolA.130.370.

[13] Kanca, E., Karahan, I.H., Eyercioglu, O., (2008). Shear-surface improvement of the austenitic stainless steel AISI 304 using high-speed punching. Optoelectronics and Advanced Materials-Rapid Communications, vol. 2, no. 12, p. 822-827.

[14] Al-Momani, E.S., Mayyas, A.T., Rawabdeh, I., Alqudah, R. (2012). Modeling blanking process using multiple regression analysis and artificial neural networks. Journal of Materials Engineering and Performance, vol. 21, no. 8, p. 1611-1619, DOI:10.1007/s11665-011-0079-x.

[15] Hu, D.C., Chen, M.-H., Ouyang, J.D., Yin, L.M. (2015). Finite element analysis of the thermal effect in high-speed blanking of thick sheet metal. The International Journal of Advanced Manufacturing Technology, vol. 80, no. 9, p. 1481-1487, D0l:10.1007/s00170-015-6954-0.

[16] Magesh, V., Sundar, S., Karuppudaiyan, S. (2016). Finite element analysis of wrinkling and shearing of sheet metal 
forming. Indian Journal of Science and Technology, vol. 9, no. 34, p. 1-5, D0l:10.17485/ijst/2016/v9i34/95252.

[17] Hambli, R., Guerin, F. (2003). Application of a neural network for optimum clearance prediction in sheet metal blanking processes. Finite Elements in Analysis and Design, vol. 39, no. 11, p. 1039-1052, Dol:10.1016/S0168-874X(02)00155-5.

[18] Hambli, R., Richir, S., Crubleau, P., Taravel, B. (2003). Prediction of optimum clearance in sheet metal blanking processes. International Journal of Advanced Manufacturing Technologies, vol. 22, no. 1, p. 20-25, Dol:10.1007/s00170002-1437-5.

[19] Mole, N., Cafuta, G., Štok, B., (2013). A method for optimal blank shape determination in sheet metal forming based on numerical simulations. Stojniški vestnik - Journal of Mechanical Engineering, vol. 59, no. 4, p. 237-250, DOI:10.5545/sv-jme.2012.989.

[20] Behrens, B., Bouguecha, A., Vucetic, M., Krimm, R., Hasselbusch, T., Bonk, C. (2014). Numerical and experimental determination of cut-edge after blanking of thin steel sheet of DP1000 within use of stress based damage model. Procedia Engineering, vol. 81, p. 1096-1101, D0I:10.1016/j. proeng.2014.10.200.
[21] Soares, J.A., Gipiela, M.L., Lajarin, S.F., Marcondes, P.V.P. (2013). Study of the punch-die clearance influence on the sheared edge quality of thick sheets. The International Journal of Advanced Manufacturing Technology, vol. 65, no. 1-4, p. 451-457, D0l:10.1007/s00170-012-4184-2.

[22] Samuel, M. (1998). FEM simulations and experimental analysis of parameters of influence in the blanking process. Journal of Materials Processing Technology, vol. 84, no. 1-3, p. 97-106, DOl:10.1016/S0924-0136(98)00083-1.

[23] Pepelnjak, T., Magoč, V., Barišič, B. (2012). Analysis of shear hat test in digital environment. Metalurgija, vol. 51, no. 2, p. 153-156.

[24] ASM Aerospace Specification Metals Inc. (2016). AISI Type 304 Stainless Steel, from http://asm.matweb.com/search/ SpecificMaterial.asp?bassnum=MQ304A, accessed on 201611-27.

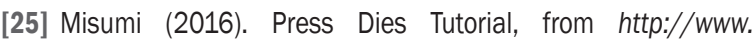
misumitechcentral.com/tt/en/press/2012/05/124-pressforming-force-1-blanking-force.html, accessed on 2016-1128. 